\title{
KAJIAN GEOTEKNIK KESTABILAN LERENG PADA PT. INDOASIA CEMERLANG SITE KINTAP KECAMATAN SUNGAI CUKA KABUPATEN TANAH LAUT PROFINSI KALIMANTAN SELATAN
}

\author{
Refky Adi Nata ${ }^{1}$, Zikri Prima Zulfira ${ }^{2}$ \\ Teknik Pertambangan, Sekolah Tinggi Teknologi Industri Padang \\ email : ${ }^{1}$ refkyadinata@ sttind.ac.id, 2primazulfira@gmail.com
}

\begin{abstract}
ABSTRAK
Pertambangan open pit pada umunnya tidak lepas dari kelerengan, Keberadaan lereng tidak hanya pada area pit penambangan saja,namun lereng juga digunakan dalam pembuatan jalan tambang, stokpile, disposal area, dan lain sebagainya. Membuat lereng yang aman secara teknis agar kestabilan lereng tercapai pada lokasi penambangan menjadi peran penting dilihat dari segi K3 dan peran penentu keberlangsungan proses penambangan untuk kedepannya.Berbicara tengtang kestabilan lereng, maka kita akan dihadapkan dengan suatu permasalahn yang menjadi kajian utama dalam kelerengan yaitu longsoran. Permasalahan ini terjadi akibat adanhya pergeseran material pembentuk lereng yang diakibatkan oleh berbagai faktor diantaraya penurunan tingkat kstabilan lereng oleh kegiatan penambangan, degradasi tanah/batuan sesuai dengan usia suatu lereng tersebut, dan lainnya. Namun pada dasarnya longsoran sering terjadi pada areal yang kurang aman (save) untuk pembuatan lereng, ditinjau dari aspek geologi, lotologi, morfologi, hidrologi dan iklim pada daerah tersebut.
\end{abstract}

Kata Kunci : lereng, Longsoran, Sudut Geser Dalam, Kuat Tekan, Kohesi, K3

\section{PENDAHULUAN}

Indonesia merupakan salah satu negara yang kaya akan sumber daya alam, termasuk didalamnya terdapat sumberdaya mineral dan batubara. Dalam perkembangannya, telah berbagai macam teknik dan teknologi yang digunakan oleh manusia dalam mengelola dan mengolah sumberdaya tersebut untuk mencapai hasil maksimal. Perusahaan yang bergerak dibidang pertambangan merupakan salah satu perusahaan yang memanfaatkan sumber daya alam tersebut. Dalam pemanfaatannya, telah banyak berbagai metode dan teknologi yang digunakan sehingga dapat diperoleh hasil yang optimal dan keuntungan yang besar, dengan biaya produksi yang relatif kecil serta ramah lingkungan.
Kajian geoteknik menjadi salah satu hal yang penting dalam dunia perlerengan terutama lereng yang ada pada tambang. Kajian ini dapat menentukan aman atau tidaknya suatu lereng dengan mengetahui tekanan dan kekuatan dari material pembentuk lereng, dan data pendukung lainnya. Hal ini akan mengacu pada K3 pekerja dalam melakukan proses penambangan kedepanya.

PT. Indoasia Cemerlang merupakan perusahaan yang bergerak dalam bidang pertambangan batubara dengan sistem open pit (tambang terbuka) dengan menggunakan metode back filling. Berdasarkan litologi yang ada, maka areal penambangan pada perusahaan ini dapat dikatakan areal dengan material pembentuk yang lunak, yaitu: claystone, mudstone, silstone, sandstone. 
Hasil pengamatan lapangan menunjukan bahwa pada beberapa lereng yang adapada areal penambangan merupakan lereng yang terbentuk dari campuran lereng yang terdiri dari lereng timbunan dan lereng origina. Maka penting untuk dilakukanya analisa kestabilan pada lereng tersebut, guna mengetahui berapa nilai dari faktor keamanan $(F K)$ pada lereng tersebut.

Berdasarkan rumusan masalah yang ada maka tujuan yang ingin dicapai dari penelitian ini adalah untuk mengetahui nilai $F K$ dari lereng original, nilai $F K$ dari lereng timbunan, dan apa saja faktor-faktor yang mempengaruhi kestabilan dari lereng tersebut, agar dapat mencapai tingkat aman pada lereng penambangan.

\section{METODOLOGI}

\subsection{Gambaran Umum Wilayah Studi}

PT. Indoasia Cemerlang Site Kintap adalah perusahaan pertambangan batubara yang terletak di wilayah Kecamatan Sungai Cuka, Kabupaten Tanah Laut, Propinsi Kalimantan Selatan. Secara geografis lokasi PT. Indoasia Cemerlang Site Kintap berada diketinggian kurang lebih 130 meter di atas permukaan laut.

Berdasarkan keputusan bupati tanah laut nomor 545/07-IUP.EKS/DPE/ tentang persetujuan izin usaha pertambangan eksplorasi kepada PT. Indoasia Cemerlang (KW. 209 / TW.1) yang merupakan revisi dari keputusan bupati tanah laut sebelumnya yaitu keputusan nomor 545/02IUP.OP/DPE/2009, maka kegiatan aktivitas penambangan dilakukan tertanggal 11 Maret 2010. Dan berdasarkan pada hasil eksplorasi ulang dan detil bahan galian batubara PT. Indoasia Cemerlang berada dalam konsesi izin eksplorasi dengan luas 672,914 ha dan 44,09 ha.

Secara geografis, lokasi kegiatan terletak pada koordinat antara $314209 \mathrm{mE}$ $315963 \mathrm{mE}$ dan $9582565 \mathrm{mN}$ - 9584301 $\mathrm{mN}$.

\subsection{Waktu dan Tempat}

Penelitian ini akan dilakukan pada PT. Indoasia Cemerlang site kintap, Kecamatan Sungai Cuka, Kabupaten Tanah Laut, Profinsi Kalimantan Selatan, analisa kestabilan lereng pada pit highwall front tambang. Penelitian ini dilakukan pada 14 Agustus sampai 14 September 2017.

\subsection{Data}

Data yang dibutuhkan untuk penelitian ini adalah:

1. Peta situasi dari section yang akan di analisis

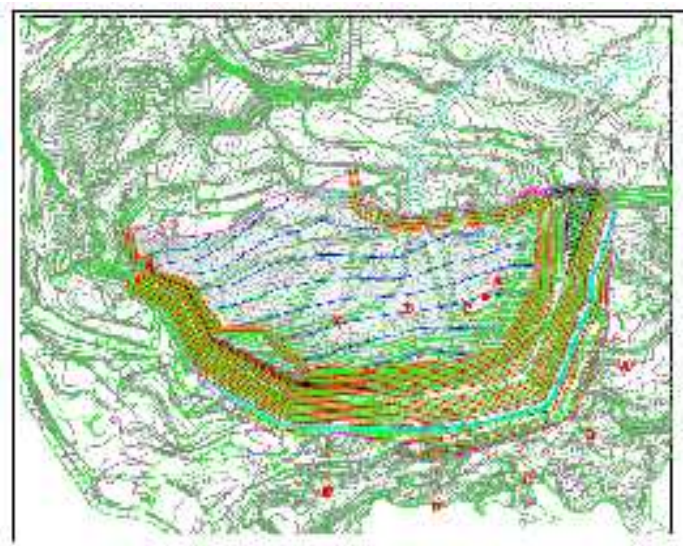

Gambar 1. Peta situasi dari section

2. Data nilai kohesi, bobot isi, dan sudut geser dalam dari masing-masing material.

Tabel 1. nilai kohesi, bobot isi, dan sudut geser dalam dari masing-masing material.

\begin{tabular}{|c|c|c|c|}
\hline Litologi & $\begin{array}{c}\text { Bobot Isi } \\
\text { Jenuh } \\
\left(\mathrm{Kn} / \mathrm{m}^{3}\right)\end{array}$ & $\begin{array}{c}\text { Kohesi } \\
\left(\mathrm{Kn} / \mathrm{m}^{2}\right)\end{array}$ & $\begin{array}{c}\text { Sudut } \\
\text { Geser } \\
\text { Dalam } \\
\left({ }^{\circ}\right)\end{array}$ \\
\hline Claystone & 19.61 & 179.03 & 12.89 \\
\hline Mudstone & 19.22 & 130.23 & 17.28 \\
\hline Silstone & 19.96 & 144.58 & 17.97 \\
\hline Sandstone & 19.42 & 128.99 & 15.38 \\
\hline
\end{tabular}

3. Data koordinat section lereng Tabel 2. Koordinat section lereng original 


\begin{tabular}{|c|c|c|}
\hline \multirow{2}{*}{ No } & \multicolumn{2}{|c|}{ Koordinat } \\
\cline { 2 - 3 } & $\mathrm{X}$ & $\mathrm{Y}$ \\
\hline 1 & 315290.95 & 9582773.00 \\
2 & 315383.35 & 9582972.41 \\
3 & 315387.48 & 9582775.00 \\
4 & 315391.94 & 9582775.00 \\
5 & 315397.09 & 9582783.00 \\
6 & 315401.55 & 9582783.00 \\
7 & 315406.71 & 9582791.00 \\
8 & 315411.17 & 9582791.00 \\
9 & 315416.32 & 9582799.00 \\
10 & 315420.78 & 9582799.00 \\
11 & 315425.94 & 9582807.00 \\
12 & 315430.59 & 9582807.29 \\
13 & 315435.52 & 9582815.00 \\
14 & 315439.93 & 9582815.00 \\
15 & 315445.02 & 9582823.00 \\
16 & 315449.43 & 9582823.00 \\
17 & 315454.52 & 9582831.00 \\
18 & 315471.06 & 9582831.00 \\
19 & 315476.15 & 9582839.00 \\
20 & 315480.56 & 9582839.00 \\
\hline
\end{tabular}

4. Data Koordinat Material section original

Tabel 3. Koordinat Material section

\begin{tabular}{|c|c|c|}
\hline \multirow{2}{*}{ No } & \multicolumn{2}{|c|}{ Koordinat } \\
\cline { 2 - 3 } & $\mathrm{X}$ & $\mathrm{Y}$ \\
\hline 1 & 315384.172 & 9582769.886 \\
3 & 315828.698 & 9582727.246 \\
4 & 315386.178 & 9582772.979 \\
5 & 315828.698 & 9582730.359 \\
6 & 315387.363 & 9582774.818 \\
7 & 315402.098 & 9582783.849 \\
8 & 315828.698 & 9582742.762 \\
9 & 315404.229 & 9582787.154 \\
10 & 315828.698 & 9582744.534 \\
11 & 315406.024 & 9582789.937 \\
12 & 315828.698 & 9582747.316 \\
13 & 315412.228 & 9582792.644 \\
14 & 315828.698 & 9582750.649 \\
15 & 315422.122 & 9582801.080 \\
16 & 315828.698 & 9582760.083 \\
17 & 315424.605 & 9582804.931
\end{tabular}

\begin{tabular}{|l|l|l|}
18 & 315828.698 & 9582762.310 \\
19 & 315432.435 & 9582810.175 \\
20 & 315828.698 & 9582767.554 \\
21 & 315434.757 & 9582813.806 \\
22 & 315828.698 & 9582771.435 \\
23 & 315443.880 & 9582821.209 \\
24 & 315828.698 & 9582779.818 \\
25 & 315450.343 & 9582824.436 \\
26 & 315828.698 & 9582781.814 \\
27 & 315453.723 & 9582829.748 \\
28 & 315828.698 & 9582787.126 \\
29 & 315460.331 & 9582831.000 \\
30 & 315828.698 & 9582789.129 \\
31 & 315481.053 & 9582839.775 \\
32 & 315828.698 & 9582800.260 \\
33 & 315500.317 & 9582856.203 \\
34 & 315828.698 & 9582818.878 \\
35 & 315511.206 & 9582866.388 \\
36 & 315828.698 & 9582830.300 \\
37 & 315521.957 & 9582876.355 \\
38 & 315828.698 & 9582841.489 \\
39 & 315531.145 & 9582882.345 \\
\hline
\end{tabular}

5. Data koordinat water table

Tabel 4. koordinat water table

\begin{tabular}{|c|c|c|}
\hline \multirow{2}{*}{ No } & \multicolumn{2}{|c|}{ Koordinat } \\
\cline { 2 - 3 } & $\mathrm{X}$ & $\mathrm{Y}$ \\
\hline 1 & 315828.698 & 9582877.809 \\
2 & 315644.829 & 9582877.809 \\
3 & 315611.740 & 9582854.961 \\
4 & 315588.440 & 9582837.382 \\
5 & 315548.284 & 9582801.596 \\
6 & 315500.638 & 9582777.474 \\
7 & 315383.350 & 9582768.590 \\
8 & 315039.078 & 9582773.000 \\
\hline
\end{tabular}

\subsection{Pengolahan Data}

Tahap pengolahan data yang dilakukan pada kasus ini yaitu mengolah data-data menggunakan softwere slode 6.004. tahapannya yaitu:

1. Memasukan koordinat section pada softwere yang telah diaktifkan untuk membuat boundary. 
2. Penginputan data material boundary, untuk mengetahui bentuk lapisan material pada section.

3. Penginputan data karakteristik batuan kedalam kolom material propertis,agar dapat memberaikan nilai masing-masing karakteristik dari material dan pemberian warna perlapisan.

4. Memasukan data koordinat Ground Water

5. Membuatan grid pada lereng, untuk mengetahui berapa nilai $F K$ dari lereng tersebut, dan poin pada grid akan menentukan berapa banyaknya analisis yang dilakukan oleh softwere pada lereng tersebut.

6. Melakukan Compute pada analisis, agar komputer dapat menganalisis data dari gride yang akan menganalisis berapa nilai $F K$ yang didapat.

7. Menampilkan nilai $F K$ lereng dengan proses interperet, setelah menekan gambar interperet maka nilai $F K$ akan ditampilkan oleh softwere.

\section{HASIL DAN PEMBAHASAN}

Gambar-gambar di bawah ini merupakan nilai $F K$ hasil pengolahan menggunakan softwere, yaitu:

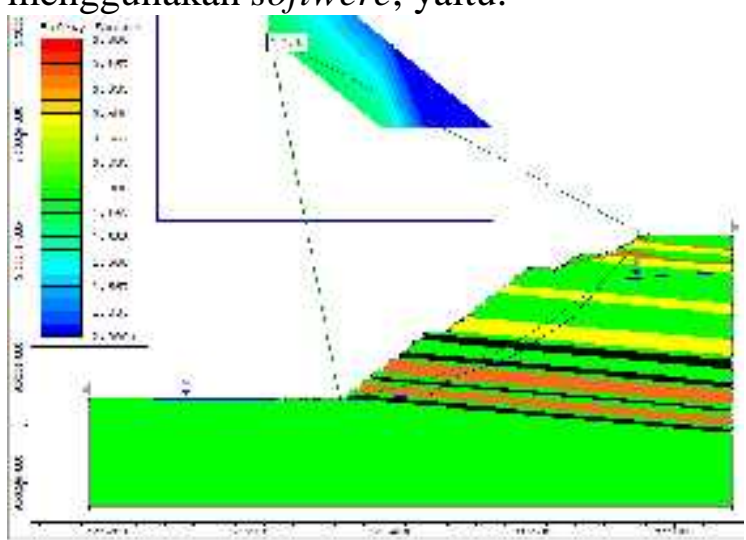

Gambar 2. Hasil pengolahan softwere pada section_A

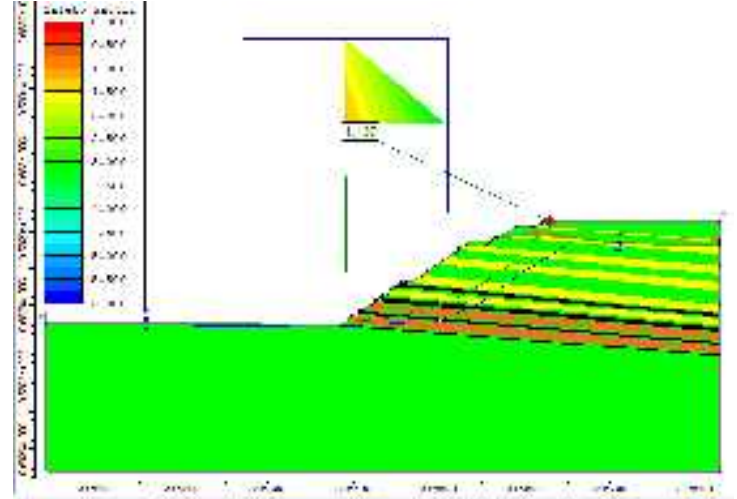

Gambar 3. Hasil pengolahan softwere pada section_B

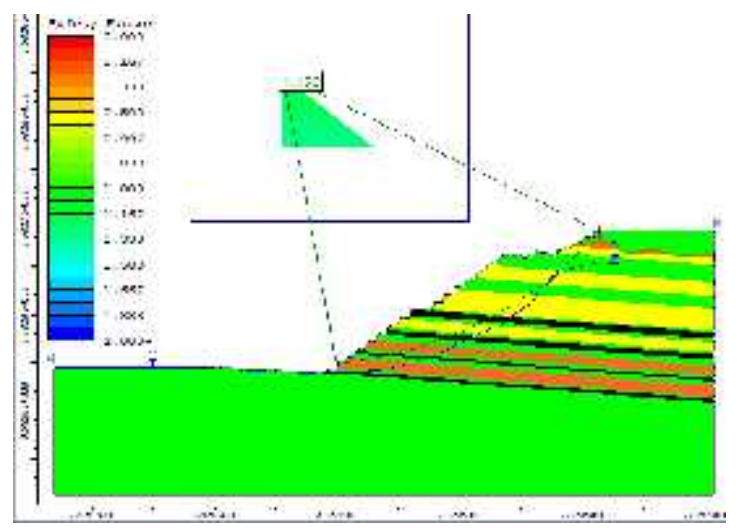

Gambar 4. Hasil pengolahan softwere pada

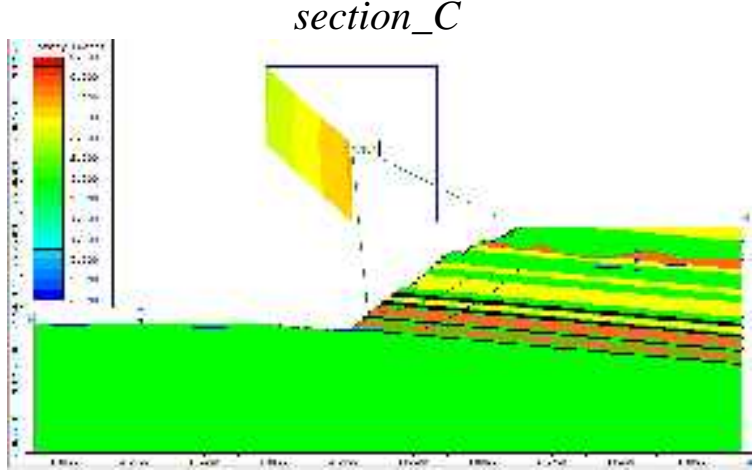

Gambar 5. Hasil pengolahan softwere pada

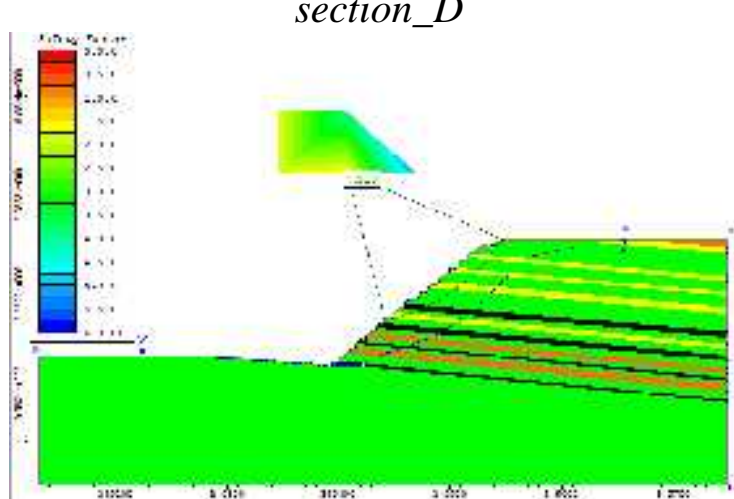

Gambar 6. Hasil pengolahan softwere pada section_E 
Dengan adanya analisis pada lereng yang dilakukan melalui beberapa section pada PIT PT. Indoasia Cemerlang, maka didapat hasil, yaitu:

1. Dari hasil pengolahan data, nilai $F K$ yang di dapat untuk section_E (lereng original) PT. Indoasia Cemerlang adalah: 1.590 (lereng relatif stabil).

2. Untuk lereng campuran pada pit PT. Indoasia Cemerlang adalah:
a. Section_A(1.136)
b. Section_B (1.137)
c. Section_C (1.150)
d. Section_D (1.181)

3. Dapat disimpulkan bahwa faktor-fakator yang mempengaruhi kestabilan lereng pit PT. Indoasia Cemerlang adalah:

a. Material timbunan pembentuk lereng

b. Paritan yang berada tepat diatas lereng hight wall

c. Litologi material pembentuk lereng

\section{KESIMPULAN DAN SARAN}

\section{Kesimpulan}

Dengan adanya analisis pada lereng yang dilakukan melalui beberapa section pada PIT PT. Indoasia Cemerlang, maka didapat hasil, yaitu:

1. Dari hasil pengolahan data, nilai $F K$ yang di dapat untuk section_E (lereng original) PT. Indoasia Cemerlang adalah: 1.590 (lereng relatif stabil).

2. Untuk lereng campuran pada pit PT. Indoasia Cemerlang adalah: Section_A(1.136), Section_B (1.137), Section_C (1.150), dan Section_D (1.181).

3. Dapat disimpulkan bahwa faktor-fakator yang mempengaruhi kestabilan lereng pit PT. Indoasia Cemerlang adalah: Material timbunan pembentuk lereng, Paritan yang berada tepat diatas lereng hight wall dan Litologi material pembentuk lereng

\section{Saran}

Diharapkan agar:

1. Peningkatan controling secara continue pada lereng timbunan.

2. Pelebaran berm dan memperkecil ketinggian pada lereng timbunan.

3. Membuat catch berm selebar 15 meter antar pertemuan lereng material original dan timbunan untuk antisipasi jatuhan material pada lereng timbunan.

\section{DAFTAR PUSTAKA}

Ari, Danang S, Data-data, PT. Indoasia Cemerlang, Kintap, 2017.

Arif, Irwandy, Buku Geoteknik Tambang, PT. Gramedia Pustaka Utama, Jakarta, 2016

Report Final Geoteknik, PT. Indoasia Cemerlang, Kintap, 2015 